JUURNAL

of Health Inequalities

\title{
Effects of prenatal music stimulation on fetal cardiotocographic parameters
}

\author{
Grażyna Gebuza, Natalia Sudoł, Marzena Kaźmierczak, Agnieszka Dombrowska-Pali, \\ Małgorzata Gierszewska, Estera Mieczkowska, Maciej Socha \\ Department of Perinatology, Gynecology and Gynecologic Oncology, Collegium Medicum in Bydgoszcz, \\ Nicolaus Copernicus University, Toruń
}

\begin{abstract}
Introduction: Prenatal musical stimulation seems to be very safe, accessible to all women and the least invasive so it should be recommended in the obstetrical care. The purpose of this study was to analyze fetal cardiotocographic parameters during exposure to music.

Material and methods: 51 women in the third trimester of pregnancy at the mean gestational age of 37 weeks were involved in the study. The first Non Stress Test (NST) was conducted without music stimulation. Next two cardiotocography tests were conducted with a music stimulation. After 10 and 20 minutes of recording, a cardiotocographic analysis was printed.

Results: During the exposure to classical music, a significant increase in the number fetal movements $(p<0.0001)$, accelerations $>10$ BPM $(p<0.0003)$, accelerations $>15$ BPM $(p<0.0006)$, short-term variability $(p<0.0001)$ and long-term variability $(p<0.0001)$ was observed. Only 20 minutes of exposure to music resulted in a considerable increase in the number fetal movements $(p<0.0001)$, accelerations $>10 \mathrm{BPM}(p<0.0001)$ and accelerations $>15 \mathrm{BPM}(p<0.0001)$, short-term variability $(p<0.0001)$.

Conclusions: Exposure to the music of W.A. Mozart changed significantly more parameters of the fetus in comparison to the music by J. Strauss. An appropriately selected piece of music and the time of exposure to music is of meaning as far as the parameters of the fetus are concerned. The study should be continued, since exposure to music might also prove useful in reducing the time required for performing $\mathrm{c}(\mathrm{NST})$.
\end{abstract}

KEY WORDS: music, therapy, cardiotocography, pregnancy, nonstress test, fetal heart rate, short term variability.

ADDRESS FOR CORRESPONDENCE: Grażyna Gebuza, Department of Perinatology, Gynecology and Gynecologic Oncology, Collegium Medicum in Bydgoszcz, 1 Łukasiewicza St., 85-821 Bydgoszcz, Poland,

e-mail: grazyna.gebuza@cm.umk.pl

\section{INTRODUCTION}

Therapeutic effects of music are applied in many areas of medicine. Musical stimulation affects physical and mental sphere of humans, triggering an emotional reaction similar to a pleasant experience or happiness [1]. Exposure to music causes a release of endorphins and oxytocin [2]. Nelson et al. showed that reports from intensive care wards indicate that music stimulates physiological processes and may serve a complementary role in specialist care [3]. Authors suggest that music may serve as a tool to partially restore the disturbed homeostasis observed in intensive care patients and it can also help in reducing pain and the need to use sedation. They hypothesize that music reduces alterations in the hypothalamic-anterior pituitary-peripheral hormone axes producing cortisol and the growth hormone and suggested that music can also increase the levels of growth hormone, which, in turn, can induce a decreased production of cytokines such as IL-6 by white blood cells. Other study reported a decrease in arterial blood pressure, pulse and cortisol levels [4].

The developments in monitoring technologies using ultrasound techniques that are currently available allow us to study the behavior of the fetus during its exposure 
to music. Research studies have shown that a baby developing in the mother's uterus is capable of hearing as early as in the $16^{\text {th }}$ week and its reaction to acoustic sounds becomes more intense with each day $[5,6]$. Sounds from the external environment reach the tissues and fluids surrounding the fetal head within the uterus through bone conduction pathways. The sounds reaching the fetus are dominated by low-frequency energy, while frequency above $0.5 \mathrm{kHz}$ is attenuated by 40 to $50 \mathrm{~dB}[5,6]$. The fetus inside the uterus responds to sounds coming from the outside through movement and changes in the heart rate. In a similar study, behavioral changes during exposure to music were observed in $87 \%$ of the fetuses [7]. These changes consisted in moving their heads and limbs, changing facial expression, opening their mouths wide and protruding their tongues. Authors of the study have suggested that music stimulates brain circuits responsible for language and communication, which translates into vocalizing movements [7]. Other observation shows that fetuses are able to listen actively and they are very sensitive to the mother's voice. They distinguish the voice of the mother from voices of other persons [8]. Depending on the type of the stimulus delivered, they show an immediate response and a change in behavior. Hearing the syllable $\mathrm{La}$ uttered by the mother, the fetuses reacted by opening their mouths wide. A stronger reaction to the syllable $L a$ was observed as compared to $L u$. Researchers suggested that such early imitative reactions may play a significant role in emotional and behavioral development as well as improve the relationship between the mother and the infant $[9,10]$. Other report indicates that exposing fetuses to the music of Wolfgang Amadeus Mozart (Mozart, AM) and Johann Strauss (Strauss, JS) results in improved cardiotocographic parameters. A higher number of fetal movements (FM), accelerations and short-term variability episodes was observed, which proved to be an indicator of the well-being of the fetus [11]. Following the exposure to Johannes Brahms's "Lullaby", an increase in cardiac activity was observed in fetuses older than 33 weeks, and a change in body movements in those older than 35 weeks [12]. Music evokes effects in every clinical situation. In a group of preeclamptic women, an improvement of cardiotocographic parameters, including the number of movements and the baseline fetal heart rate, was observed compared to the control group [13]. Prenatal music intervention could be a useful and effective tool to reduce anxiety in full-term pregnant women during an Non Stress Test (NST) and improve the delivery process by reducing the first stage of labor in nulliparous women [14]. After the NST, the women from the music group showed significantly lower scores in state anxiety, as well as trait anxiety than the control group. Furthermore, the pregnant women from the music group presented lower levels of state-trait anxiety than the control group in relation to the variables of birth process, and higher birth weight and chest circum- ference in the newborn [15]. Reports by other authors also confirm the positive effect of exposure to music in the perinatal stage [16-18].

The literature discussed above clearly indicates that the exposure to musical sounds evokes positive health-related effects. Scientific reports on the impact of music on cardiotocographic parameters of the fetus are scarce, and in the majority of cases they concern the baseline heart rate and FM. In a study by Gebuza et al., the number of FM, accelerations, and episodes of high and short-term variability (STV) increased significantly during the exposure to classical music by Mozart ("Turkish March") and Strauss ("Tritsch-Tratsch Polka") [11].

The aim of this study was to observe whether fetal exposure to other classical music pieces by Strauss Voces de Primavera (JS) and Mozart - Piano Concerto No. 21 Andante (AM) would evoke comparable effects.

\section{MATERIAL AND METHODS}

The study was authorized by the Bioethics Committee (No. 224/2017). Research data was collected in 2018. The patients were informed about the purpose of the study and gave informed consent to participate. The study involved 51 women in the third trimester of pregnancy, patients in the third-referral clinical ward at the Regional Polyclinical Hospital in Torun (Poland). The patients were admitted to the Pregnancy Pathology Unit for various conditions that included: gestational diabetes, arterial hypertension, intrahepatic cholestasis of pregnancy, hypothyroidism, intrauterine growth restriction (Table 1). The NST was performed using the Sonicaid Team Standard cardiotocograph by Oxford, as it allows to print out cardiotocographic readings after 10 minutes of NST measurement. Cardiotocographic parameters were eval-

\section{TABLE 1. Causes of the hospitalization}

\begin{tabular}{|l|c|c|}
\hline Medical diagnosis & $n$ & $\%$ \\
\hline IVF (In vitro fertilization) & 1 & 1.9 \\
\hline Anemia & 1 & 1.9 \\
\hline $\begin{array}{l}\text { ICP (Intrahepatic cholestasis of pre- } \\
\text { gnancy) }\end{array}$ & 3 & 5.8 \\
\hline Premature rupture of membrane & 3 & 5.8 \\
\hline Gestational diabetes & 6 & 11.7 \\
\hline Cervical incompetence & 2 & 3.9 \\
\hline IUGR (Intrauterine growth restriction) & 4 & 7.8 \\
\hline Induction of labor & 3 & 5.8 \\
\hline Hyperthyroidism & 1 & 1.9 \\
\hline Hypothyroidism & 2 & 3.9 \\
\hline Arterial hypertension & 7 & 13.2 \\
\hline Threatened preterm labor (TPL) & 6 & 11.7 \\
\hline Fetal observation & 12 & 23.5 \\
\hline In all & 51 & 100 \\
\hline
\end{tabular}


uated using the Monako System Module MT-2 - Multi-station Obstetric Surveillance System (ITAM, Zabrze, Poland). The evaluated parameters were: the fetal heart rate; the number of Fetal movements (FM); the number of uterine contractions; the number of accelerations above 10 Baseline Fetal Heart Rate (BPM), lasting for over 10 seconds; the number of accelerations above $15 \mathrm{BPM}$, lasting over 15 seconds; short-term and long-term variability. The music was played from a music player (computer notebook) at the volume of $65 \mathrm{~dB}$. Prior to commencing the study, the respondents were requested to lie down in the left lateral recumbent position and an NST was conducted with no musical exposure. It was followed by a cardiotocographic analysis. The first NST was conducted without music stimulation. It lasted for 10 minutes and a cardiotocograph analysis was printed afterwards. Next, an NST recording lasting $20 \mathrm{~min}$ utes was conducted. During the NST, classical music by Strauss - Voces de Primavera was played. After 10 and 20 minutes of recording, a cardiotocographic analysis was printed. Then the piece by Mozart - Piano Concerto No. 21 Andante was played for 20 minutes. After 10 and 20 minutes of recording, a cardiotocographic analysis was printed. The piece of music by Strauss - Voces de Primavera has the character of a moderate waltz. The musical work of Mozart begins very quietly, with a march. It has the character of a lyrical melody. The music is intertwined, its pace grows rapidly and later it becomes quiet.

Statistical analysis was conducted using the PQStat software version 1.6.4.122 (Poznan, Poland). Cardiotocographic variables of the heart of the fetus before and during classical music sessions in subsequent measurement points were compared with the usage of Friedman's test and post-hoc with Bonferroni's test. A two-tailed $p$ value of less than 0.05 was considered statistically significant.

\section{RESULTS}

The study involved 51 women in the third trimester of pregnancy, 27 (52.9\%) women were primigravidae, the remaining $24(47.1 \%)$ were multigravidae. Table 2 presents descriptive statistics of the group.

Table 3 presents the values of cardiotocographic parameters before and during exposure to classical music by Strauss - Voces de Primavera and Mozart - Piano Concerto No. 21 Andante. No significant difference was observed in each of the measurement points $(p>0.05)$ as a result of the analysis of the basic fetal heart rate.
When analyzing the number of FM, a significant difference in the measurement points was observed $(p<0.01)$. The FM values increased during the exposure to music (2.3 vs 5.6 and 4.5 ). The parameters without music stimulation were considerably lower than the values which were observed during the exposure to music by JS and AM after 20 minutes $(p<0.01)$. No significant difference was found between FM without music stimulation and the parameters observed during the exposure to music by JS and AM after 10 minutes $(p>0.05)$. During the stimulation with music by JS and AM, a significant difference between the period after 10 minutes and after 20 minutes $(p<0.05)$ was found. The number of FM during the stimulation with music by JS and AM was significantly higher than the number of FM without the exposure to music.

When analyzing the number of uterine contractions, no difference in the measurement points $(p>0.05)$ was found. Although the analyzes did not show significant differences in measurements, it was observed that the number of uterine contractions in women decreased during the music session ( 0.41 vs 0.14 and 0.22 ).

The analysis of the acceleration number above $10 \mathrm{BPM}$, lasting over 10 seconds showed a significant difference in the measurement points $(p<0.01)$. The acceleration values increased, the longer the fetus was exposed to music ( 0.86 vs 1.78 and 1.53 ). The parameters without music stimulation were significantly lower than the values during the music sessions by JS and AM after 20 minutes $(p<0.01)$. There was no significant difference between the parameters without music stimulation and the parameters during the session of music by JS and AM after 10 minutes $(p>0.05)$.

The interpretation of the number of accelerations over 15 BPM, lasting 15 seconds, showed a significant difference in the measurement points $(p<0.01)$. The acceleration values increased the longer was the exposure to music (1.49 vs 1.92 and 2.27). The parameters observed without music stimulation were significantly lower than the parameters found during the stimulation with the music by AM after 20 minutes $(p<0.05)$. However, no significant difference was found between the parameters found without music stimulation and the parameters observed during the exposure to music by JS after 20 minutes, despite the fact that higher values were achieved $(p>0.05)$.

The analysis of the number of episodes of short-term variability (STV) showed a significant difference in the

TABLE 2. Descriptive statistics of the group

\begin{tabular}{|l|c|c|c|c|c|c|c|c|}
\hline Parameter & $n$ & Mean & Median & SD & Min & Max & Q1 & Q2 \\
\hline Week of pregnancy & 51 & 37 & 38 & 2.49 & 33 & 42 & 35 & 39 \\
\hline Women's age & 51 & 27.62 & 28 & 5.36 & 18 & 38 & 24 & 31 \\
\hline
\end{tabular}


TABLE 3. Comparison of cardiotocographic parameters before and during exposure to music

\begin{tabular}{|c|c|c|c|c|c|c|c|c|c|c|c|}
\hline \multirow[t]{2}{*}{ Parameters } & \multirow[t]{2}{*}{ Mean } & \multirow{2}{*}{$\begin{array}{l}\text { Standard } \\
\text { deviation }\end{array}$} & \multirow{2}{*}{$\begin{array}{l}\text { Mini- } \\
\text { mum }\end{array}$} & \multirow[t]{2}{*}{ Median } & \multirow{2}{*}{$\begin{array}{l}\text { Maxi- } \\
\text { mum }\end{array}$} & \multirow{2}{*}{$\begin{array}{l}\text { Friedman } \\
\text { test }\end{array}$} & \multicolumn{5}{|c|}{ Post-hoc } \\
\hline & & & & & & & Before & $\begin{array}{l}\text { JS } \\
10 \mathrm{~min}\end{array}$ & $\begin{array}{c}\text { JS } \\
20 \mathrm{~min}\end{array}$ & $\begin{array}{c}\text { MA } \\
10 \mathrm{~min}\end{array}$ & $\begin{array}{c}\text { MA } \\
20 \mathrm{~min}\end{array}$ \\
\hline \multicolumn{12}{|l|}{$\begin{array}{l}\text { Baseline fetal } \\
\text { heart rate }\end{array}$} \\
\hline Before & 139.5 & 8.72 & 120.6 & 139.6 & 160.1 & \multirow{5}{*}{$\begin{array}{l}\mathrm{H}=2.3733 \\
p=0.6675\end{array}$} & & 1 & 1 & 1 & 1 \\
\hline JS $10 \mathrm{~min}$ & 140.0 & 9.85 & 118.4 & 140.1 & 163.5 & & 1 & & 1 & 1 & 1 \\
\hline JS $20 \mathrm{~min}$ & 141.8 & 9.26 & 117.7 & 141.1 & 162.1 & & 1 & 1 & & 1 & 1 \\
\hline AM $10 \mathrm{~min}$ & 142.8 & 10.55 & 118.8 & 144.1 & 162.5 & & 1 & 1 & 1 & & 1 \\
\hline AM 20 min & 141.8 & 9.83 & 122.5 & 138.8 & 166.5 & & 1 & 1 & 1 & 1 & \\
\hline \multicolumn{12}{|l|}{$\begin{array}{l}\text { Fetal } \\
\text { movements }\end{array}$} \\
\hline Before & 2.37 & 5.34 & 0.00 & 1.00 & 29.00 & \multirow{5}{*}{$\begin{array}{l}\mathrm{H}=42.401 \\
p<0.0001\end{array}$} & & 1 & 0.00 & 1 & $<0.00$ \\
\hline JS 10 min & 3.45 & 10.75 & 0.00 & 1.00 & 76.00 & & 1 & & 0.01 & 1 & 0.00 \\
\hline JS $20 \mathrm{~min}$ & 5.61 & 16.41 & 0.00 & 2.00 & 117.0 & & 0.00 & 0.01 & & 0.05 & 1 \\
\hline $\mathrm{AM} 10 \mathrm{~min}$ & 3.08 & 7.58 & 0.00 & 1.00 & 46.00 & & 1 & 1 & 0.05 & & 0.01 \\
\hline $\mathrm{AM} 20 \mathrm{~min}$ & 4.57 & 7.88 & 0.00 & 2.00 & 51.00 & & $<0.00$ & 0.00 & 1 & 0.01 & \\
\hline \multicolumn{12}{|l|}{ Contractions } \\
\hline Before & 0.41 & 1.25 & 0.00 & 0.00 & 8.00 & \multirow{5}{*}{$\begin{array}{l}\mathrm{H}=2.845 \\
p=0.5841\end{array}$} & & 1 & 1 & 1 & 1 \\
\hline JS 10 min & 0.14 & 0.35 & 0.00 & 0.00 & 1.00 & & 1 & & 1 & 1 & 1 \\
\hline JS $20 \mathrm{~min}$ & 0.14 & 0.35 & 0.00 & 0.00 & 1.00 & & 1 & 1 & & 1 & 1 \\
\hline AM $10 \mathrm{~min}$ & 0.24 & 0.62 & 0.00 & 0.00 & 3.00 & & 1 & 1 & 1 & & 1 \\
\hline $\mathrm{AM} 20 \mathrm{~min}$ & 0.22 & 0.61 & 0.00 & 0.00 & 3.00 & & 1 & 1 & 1 & 1 & \\
\hline \multicolumn{12}{|l|}{$\begin{array}{l}\text { Accelerations } \\
>10 \text { BPM }\end{array}$} \\
\hline Before & 0.86 & 0.92 & 0.00 & 1.00 & 4.00 & \multirow{5}{*}{$\begin{array}{l}\mathrm{H}=21.298 \\
p=0.0003\end{array}$} & & 0.53 & 0.00 & 1 & 0.00 \\
\hline JS $10 \mathrm{~min}$ & 1.27 & 1.23 & 0.00 & 1.00 & 6.00 & & 0.53 & & 1 & 1 & 1 \\
\hline JS 20 min & 1.78 & 1.82 & 0.00 & 1.00 & 10.00 & & 0.00 & 1 & & 0.49 & 1 \\
\hline AM $10 \mathrm{~min}$ & 1.20 & 1.17 & 0.00 & 1.00 & 6.00 & & 1 & 1 & 0.49 & & 0.71 \\
\hline AM $20 \mathrm{~min}$ & 1.53 & 1.33 & 0.00 & 1.00 & 6.00 & & 0.00 & 1 & 1 & 0.71 & \\
\hline \multicolumn{12}{|l|}{$\begin{array}{l}\text { Accelerations } \\
>15 \text { BPM }\end{array}$} \\
\hline Before & 1.49 & 1.46 & 0.00 & 1.00 & 8.00 & \multirow{5}{*}{$\begin{array}{c}\mathrm{H}=19.5929 \\
p=0.0006\end{array}$} & & 1 & 1 & 1 & 0.01 \\
\hline JS $10 \mathrm{~min}$ & 1.67 & 2.01 & 0.00 & 1.00 & 10.00 & & 1 & & 1 & 1 & 0.00 \\
\hline JS 20 min & 1.92 & 2.14 & 0.00 & 1.00 & 11.00 & & 1 & 1 & & 1 & 0.56 \\
\hline AM $10 \mathrm{~min}$ & 1.47 & 1.57 & 0.00 & 1.00 & 9.00 & & 1 & 1 & 1 & & 0.03 \\
\hline AM $20 \mathrm{~min}$ & 2.27 & 1.83 & 0.00 & 2.00 & 9.00 & & 0.01 & 0.00 & 0.56 & 0.03 & \\
\hline \multicolumn{12}{|l|}{$\begin{array}{l}\text { Short-term } \\
\text { variability }\end{array}$} \\
\hline Before & 7.73 & 2.40 & 3.50 & 6.90 & 14.60 & \multirow{5}{*}{$\begin{array}{c}\mathrm{H}=31.2537 \\
p<0.0001\end{array}$} & & 1 & 1 & 0.14 & 0.00 \\
\hline JS $10 \mathrm{~min}$ & 7.44 & 2.11 & 2.00 & 7.40 & 13.50 & & 1 & & 0.30 & 0.02 & $<0.00$ \\
\hline JS 20 min & 8.11 & 2.64 & 4.40 & 7.50 & 17.10 & & 1 & 0.30 & & 1 & 0.05 \\
\hline $\mathrm{AM} 10 \mathrm{~min}$ & 8.32 & 2.28 & 4.40 & 8.10 & 13.00 & & 0.14 & 0.02 & 1 & & 0.56 \\
\hline AM $20 \mathrm{~min}$ & 9.68 & 4.29 & 2.50 & 9.00 & 34.60 & & 0.00 & $<0.00$ & 0.05 & 0.56 & \\
\hline
\end{tabular}


TABLE 3. Cont.

\begin{tabular}{|c|c|c|c|c|c|c|c|c|c|c|c|}
\hline \multirow[t]{2}{*}{ Parameters } & \multirow[t]{2}{*}{ Mean } & \multirow{2}{*}{$\begin{array}{l}\text { Standard } \\
\text { deviation }\end{array}$} & \multirow{2}{*}{$\begin{array}{l}\text { Mini- } \\
\text { mum }\end{array}$} & \multirow[t]{2}{*}{ Median } & \multirow{2}{*}{$\begin{array}{l}\text { Maxi- } \\
\text { mum }\end{array}$} & \multirow{2}{*}{$\begin{array}{l}\text { Friedman } \\
\text { test }\end{array}$} & \multicolumn{5}{|c|}{ Post-hoc } \\
\hline & & & & & & & Before & $\begin{array}{c}\text { JS } \\
10 \mathrm{~min}\end{array}$ & $\begin{array}{c}\text { JS } \\
20 \mathrm{~min}\end{array}$ & $\begin{array}{c}\text { MA } \\
10 \mathrm{~min}\end{array}$ & $\begin{array}{c}\text { MA } \\
20 \mathrm{~min}\end{array}$ \\
\hline \multicolumn{12}{|l|}{$\begin{array}{l}\text { Long-term } \\
\text { variability }\end{array}$} \\
\hline Before & 46.94 & 13.22 & 14.80 & 45.70 & 74.90 & \multirow{5}{*}{$\begin{array}{c}\mathrm{H}=30.8016 \\
p<0.0001\end{array}$} & & 1 & 1 & 1 & 0.00 \\
\hline JS $10 \mathrm{~min}$ & 46.37 & 11.91 & 22.30 & 45.10 & 70.10 & & 1 & & 0.18 & 0.35 & $<0.00$ \\
\hline JS 20 min & 49.34 & 12.31 & 26.80 & 47.00 & 77.60 & & 1 & 0.18 & & 1 & 0.04 \\
\hline $\mathrm{AM} 10 \mathrm{~min}$ & 49.43 & 10.39 & 29.60 & 49.10 & 73.30 & & 1 & 0.35 & 1 & & 0.02 \\
\hline $\mathrm{AM} 20 \mathrm{~min}$ & 54.19 & 10.97 & 28.50 & 55.50 & 78.30 & & 0.00 & $<0.00$ & 0.04 & 0.02 & \\
\hline
\end{tabular}

measurement points $(p<0.01)$. The STV values increased the longer the exposure to music was ( 7.73 vs 8.11 and 9.68). The STV parameters without music stimulation were significantly lower than the values during the exposure to music by AM after 20 minutes $(p<0.05)$. The STV parameters without music stimulation did not differ considerably from the values observed during the stimulation with the music by JS after 20 minutes $(p>0.05)$.

The analysis of the number of long-term variation episodes (LTV) showed a significant difference in the measurement points $(p<0.01)$. The LTV values increased the longer the exposure to music was (46.9 vs 49.34 and 54.19). The parameters observed without music stimulation were significantly lower $(p<0.05)$ than the values found during the exposure to music by AM after 20 minutes $(p<0.05)$. The LTV parameters without music stimulation were not significantly different from the values observed during the exposure to music by JS after 20 minutes $(p>0.05)$.

\section{DISCUSSION}

The present study demonstrates changes in cardiotocographic parameters during fetal exposure to classical music. When pregnant women were exposed to well-known music pieces by Johann Strauss - Voces de Primavera and Amadeus Mozart - Piano Concerto No. 21 Andante, changes in the values of cardiotocographic parameters were observed in the fetuses.

The behaviors observed were related to the character of the music played, which was both rhythmical and well-known. Responses to musical stimulation were different: there was either less FM or more intensive FM to the rhythm of the music. During the exposure to music pieces by Strauss and Mozart, significant differences in the baseline fetal heart rate were not observed, the values remained within the normal range. Strauss - Voces de Primavera and Mozart's music are rather well-known. The lack of changes that was observed might have been caused by fetal response to already familiar sounds of well-known music. In another study analyzing exposure to music by ABBA, Amadeus Mozart and Johann Strauss, values of arterial blood pressure and pulse in adult patients were compared. A significant decrease in the mentioned parameters was observed in the group listening to music by Mozart and Strauss, whereas no changes were found in the group listening to songs by ABBA [4]. In yet another study, a significant improvement in fetal parameters in NST was observed upon exposure to music by Mozart and Strauss [11]. The lack of changes in NST with exposure to popular music observed in this study is a positive result; the values remained within the normal range. At the same time, such observations show how crucial the choice of a piece of music is for reaching the desired effect. This analysis confirms previous reports by other authors, in which no significant changes in fetal heart rate during exposure to music have been found $[17,19,20]$.

Research studies on preeclamptic women demonstrated a decrease in the baseline heart rate, which was interpreted as an improvement in fetal well-being [13]. In a study by $\mathrm{Oh}$ et al., significantly lower values of the baseline fetal heart rate were observed in the group exposed to music as compared to the control group [18]. Similar observations were made in pregnant women undergoing relaxation therapy. A decreased baseline heart rate and an increased number of accelerations were observed, which was associated with an improvement in the well-being of the fetus [21]. In a different study, an increase in the baseline fetal heart rate was observed during stimulation with music and singing, as compared to the control group [16]. A similar increase in heart rate following musical stimulation was also observed by other researchers [20, 22]. In García González's research the strip charts showed a significantly increased basal fetal heart rate and higher fetal reactivity, with accelerations of fetal heart rate in pregnant women with music stimulation [23].

In this study, the number of FM increased during the exposure to music of Strauss and Mozart, the changes were significant. Reports by other researchers indicated that the number of FM increased significantly during the stimulation with music $[11,13,22]$. Fetal reactions to music differ depending on the stage of pregnancy; more body movements were observed after week 35 [12]. 
Many methods of fetal stimulation are employed in order to receive a normal, reactive cardiotocographic NST reading. Reports by Pirhadi are particularly interesting. In his study, he observed a higher number of FM following musical intervention than after vibroacoustic stimulation (VAS). Moreover, there were no significant differences in the number of FM between the VAS group and the musical group [24]. Other observations were made by Tan et al. [25] as well as Anumizmata et al. [26], who found a higher number of FM following vibroacoustic stimulation.

Reports by Voegtline et al. describe fetal response to the mother's voice. Upon exposure to the voice of their mother reading, the movement of previously inactive fetuses grew more intense and their baseline heart rate increased, whereas previously active fetuses demonstrated an orienting response through decreasing the amplitude of movements and a momentary decrease in fetal cardiac activity. The researchers decided that the intensity of fetal response to the stimulus depended on the basic heart rate variability in such a way that the strongest response was observed in fetuses with low variability, and when the mothers were resting in silence [8].

Accelerations are nearly always related to the presence of FM and they do not occur when the fetus is asleep. They appear as a projection of the normal functioning of the central and peripheral nervous system. The occurrence of acceleration precludes the presence of fetal acidosis [27]. This study revealed that the number of accelerations > $10 \mathrm{BPM}$ and accelerations > $15 \mathrm{BPM}$ during exposure to classical music increased significantly. In a studies, musical sounds played to pregnant women significantly increased the frequency of fetal heart rate accelerations as compared to the period with no musical stimulation $[20,23]$. An increase in the number of accelerations was also observed following stimulation with music by Mozart and Strauss in a study by Gebuza et al. [11] and in a study by Akbarzade et al. [21]. A different study observed a decrease in the number of accelerations. The authors interpreted this reduction in the number of accelerations as affected by the rhythm of the music used. On exposure to rhythmic, harmonic musical sounds (Maurice Ravel's "Bolero"), the fetuses were less active and moved less. Therefore, the number of accelerations decreased while short-term variability increased, which was indicative of fetal well-being [28]. Reports by other authors reveal a higher number of accelerations in groups exposed to music than in control groups $[17,18$, 22]. Studies conducted during childbirth likewise indicate a significantly higher number of accelerations and baseline heart rate in the latent phase of labor 17].

According to researchers, fetal condition should be evaluated by not only STV, but also other cardiotocographic parameters, mainly the occurrence and number of high-variability episodes [29]. Periods of fetal activity related to movements of the torso and limbs, as well as breathing movements, are reflected in fragments of cardiotocographic readings referred to as high variability episodes, which remain closely related to long-term variability $[29,30]$.

Studies by Fink showed an increase in the long-term variability of the fetal heart rate during a relaxation session following the employment of various relaxation techniques in the mothers (progressive muscle relaxation - PMR, and guided imagery - GI) [31]. In this study, the number of long-term variability increased significantly during the exposure to music by Strauss and Mozart which was a desired indicator of the well-being of the fetus.

Low variability episodes are clinically consistent with periods of rest or sleep of the fetus and may be of significance in the evaluation of fetal condition in situations related to chronic hypoxia [30,32]. Studies by Glaziors et al. showed that low variability and a low number of FM indicate a threat to the fetus [29].

In this study, short-term variability, which is recognized as an indicator in the assessment of fetal condition, was analyzed. Along with a decrease in the value of STV, the risk of metabolic acidosis increases; it reaches $80 \%$ at a value lower than $2.5[30,31]$. Lower STV values in the perinatal stage often constitute an indication for cesarean section [33].

This study demonstrated higher values of STV during musical intervention, the difference was significant. Reports by Gebuza et al. suggest that classical music effectively improves the well-being of the fetus. STV values increased following the exposure to music by Mozart and Strauss [11]. Similar observations were presented by DiPietro et al. During stimulation with relaxation music, a significant increase in the baseline heart rate variability was observed $[3,34]$. It needs to be noted that recent reports by Pirhadi demonstrate no difference in the number of FM following musical and vibroacoustic intervention [24]. It should be considered whether music can be used interchangeably with VAS if it is equally effective. It is soothing and pleasant for the hospitalized mothers and their babies [11].

This study also analyzed uterine contractions and found that their number decreased significantly during exposure to music used (0.41 vs 0.22 ). The respondents were at a mean gestational age of 37 weeks (Q1-35, Q2-39). Uterine contractions may have been desirable in this period.

A decrease in the number of uterine contractions following the musical intervention was observed in a different study [11, 28]. A higher number of contractions following the exposure to music was achieved by Poręba et al., which was desirable in that particular study group, as all the participants were due for delivery (full-term pregnancy) [20].

The above analysis indicates that a period of $10 \mathrm{~min}$ utes is insufficient for the occurrence of changes in cardiotocographic parameters. Only after 20 minutes sig- 
nificant changes were observed. The observation of the analysis of the number of FM, accelerations, short-term and long-term variability suggests that the exposure to music Mozart, despite the fact that the piece of music has a light, marching rhythm had a stronger impact on cardiotocographic parameters than the waltz of Strauss. It should be noted, however, that the work of Mozart was always played after the work of Strauss, so this result may be burdened with a systematic methodological error. Choosing the right music does not seem to be meaningless. In another study, when the fetuses were exposed to the music by Mozart and Strauss, significant differences in the cardiotocographic parameters were observed more often during the exposure to music by Mozart [11]

Results of this study are consistent with recent findings. The study revealed changes in fetal cardiotocographic parameters resulting from the exposure to music. A significant increase was observed in parameters determining the fetal well-being, such as the number of FM, short-term variability, accelerations >10 BPM, accelerations >15 BPM, short-term variability, longterm variability. An insignificant decrease was found in the number of contractions. The study indicates that fetuses are capable of hearing, which might potentially be used for perinatal screening tests in hearing diagnostics. Moreover, exposure to music contributed to reducing the number of uterine contractions. Therefore, music can be applied as a relaxation therapy in the prevention of preterm birth, in women with anxiety and in hospitalized women. The study should be continued, since exposure to music might also prove useful in reducing the time required for performing NST. Musical stimulation is inexpensive and easy to perform. Different methods for stimulating the fetus are used in perinatology, including fruit juice, chocolate, touching the mother's abdomen and vibroacoustic stimulation (VAS) in order to achieve a reactive NST result. Compared to those methods, musical stimulation seems to be the least invasive, safe and accessible to all women.

\section{CONCLUSIONS}

Exposure to music is an effective method of stimulation which can be used in perinatology. It also constitutes an initial piece of evidence proving that musical stimulation can be used in the testing of fetal hearing or as a complementary therapy for reducing stress in infancy or preventing preterm births. This might be substantiated by the reported decrease in the number of uterine contractions. Fetal behaviors changed under the influence of music, which was manifested by increased number of FM, accelerations $>10$ BPM, accelerations $>15$ BPM, short-term variability and long-term variability. Our considerations confirm that the exposure of fetuses to two different pieces of classical music lasting for 20 minutes changed the cardiotocographic parameters positively.

\section{ACKNOWLEDGMENTS}

The authors would like to thank Dr. Marek Maleńczyk at the Regional Polyclinical Hospital in Torun for assistance in conducting research. We express our gratitude to mothers and to infants involved in this study.

\section{DISCLOSURE}

The authors report no conflict of interest.

\section{References}

1. Suda M, Morimoto K, Obata A, et al. Emotional responses to music: towards scientific perspectives on music therapy. Neuroreport 2008; 19 (1): 75-78.

2. Nilsson U. Soothing music can increase oxytocin levels during bed rest after open-heart surgery: a randomised control trial. J Clin Nurs 2009; 18 (15): 2153-2161.

3. Nelson A, Hartl W, Jauch KW, et al. The impact of music on hypermetabolism in critical illness. Curr Opin Clin Nutr Metab Care 2008; 11 (6): 790-794.

4. Trappe HJ, Voit G. The cardiovascular effect of musical genres. Dtsch Arztebl Int 2016; 113 (20): 347-352.

5. Gerhardt KJ, Abrams RM. Fetal exposures to sound and vibroacoustic stimulation. J Perinatol 2000; 20 (8 Pt 2): S21-S30.

6. Sohmer H, Perez R, Sichel JY, et al. The pathway enabling external sounds to reach and excite the fetal inner ear. Audiol Neurootol 2001; 6 (3): 109-116.

7. López-Teijón M, García-Faura Á, Prats-Galino A. Fetal facial expression in response to intravaginal music emission. Ultrasound 2015; 23 (4): 216-223.

8. Voegtline KM, Costigan KA, Pater HA, DiPietro JA. Near-term fetal response to maternal spoken voice. Infant Behav Dev 2013; 36 (4): 526-533.

9. Chelli D, Chanoufi B. Audition fœtale. Mythe ou réalité? [Fetal audition. Myth or reality?]. J Gynecol Obstet Biol Reprod (Paris) $2008 ; 37$ (6): $554-558$.

10. Ferrari GA, Nicolini Y, Demuru E, et al. Ultrasonographic investigation of human fetus responses to maternal communicative and non-communicative stimuli. Front Psychol 2016; 7: 354

11. Gebuza G, Dombrowska A, Kaźmierczak M, et al. The effect of music therapy on the cardiac activity parameters of a fetus in a cardiotocographic examination. J Matern Fetal Neonatal Med 2017; 30 (20): 2440-2445.

12. Kisilevsky S, Hains SMJ, Jacquet AY, et al. Maturation of fetal responses to music. Dev Sci 2004; 7 (5): 550-559.

13. Toker E, Kömürcü N. Effect of Turkish classical music on prenatal anxiety and satisfaction: a randomized controlled trial in pregnant women with pre-eclampsia. Complement Ther Med 2017; 30: 1-9.

14. García González J, Ventura Miranda MI, Requena Mullor M, et al. Effects of prenatal music stimulation on state/trait anxiety in full-term pregnancy and its influence on childbirth: a randomized controlled trial. J Matern Fetal Neonatal Med 2018; 31 (8): 1058-1065.

15. García González J, Ventura Miranda MI, Requena Mullor M, et al. State-trait anxiety levels during pregnancy and foetal param- 
eters following intervention with music therapy. J Affect Disord 2018; 232: 17-22

16. AL-Qahtani NH. Foetal response to music and voice. Aus N Z J Obstet Gynaecol 2005; 45 (5): 414-417.

17. Simavli S, Gumus I, Kaygusuz I, Yildirim M, Usluogullari B, Kafali H. Effect of music on labor pain relief, anxiety level and postpartum analgesic requirement: a randomized controlled clinical trial. Gynecol Obstet Invest 2014; 78 (4): 244-250.

18. Oh MO, Kim YJ, Baek CH, et al. [Effect of music intervention on maternal anxiety and fetal heart rate pattern during non -stress test]. J Korean Acad Nurs 2016; 46 (3): 315-326.

19. Khoshkholgh R, Keshavarz T, Moshfeghy Z, et al. Comparison of the effects of two auditory methods by mother and fetus on the results of non-stress test (baseline fetal heart rate and number of accelerations) in pregnant women: a randomized controlled trial. J Family Reprod Health 2016; 10 (1): 27-34.

20. Poręba A, Dutkiewicz D, Drygalski M. Wpływ dźwięków muzycznych na zachowanie się wybranych parametrów kardiotokograficznych u kobiet w ciąży donoszonej [The impact of musical sounds on the behaviour of selected cardiotocographic parametres in women in full-term pregnancy]. Ginekol Pol 2000; 71 (8): 915-920.

21. Akbarzade M, Rafiee B, Asadi N, Zare N. The effect of maternal relaxation training on reactivity of non-stress test, basal fetal heart rate, and number of fetal heart accelerations: a randomized controlled trial. Int J Community Based Nurs Midwifery 2015; 3 (1): 51-59.

22. Kafali H, Derbent A, Keskin E, et al. Effect of maternal anxiety and music on fetal movements and fetal heart rate patterns. J Matern Fetal Neonatal Med 2011; 24 (3): 461-464.

23. García González J, Ventura Miranda MI, Manchon García F, et al. Effects of prenatal music stimulation on fetal cardiac state, newborn anthropometric measurements and vital signs of pregnant women: A randomized controlled trial. Complement Ther Clin Pract 2017; 27: 61-67.

24. Pirhadi M. The effect of vibroacoustic stimulation and music on fetal movement. Int J Pediatr 2015; 3 (21): 903-908.

25. Tan KH, Smyth RMD, Wei X. Fetal vibroacoustic stimulation for facilitation of tests of fetal wellbeing. Cochrane Database Syst Rev 2013; 2013 (12): CD002963.

26. Annunziata ML, Scala M, Giuliano N, et al. Fetal vibroacoustic stimulation in computerized cardiotocographic analysis: the role of short-term variability and approximate entropy. J Pregnancy 2012; 2012: 814987.

27. Cunningham FG, Leveno KJ, Bloom SL, et al. Intrapartum assessment. In: William's Obstetrics $22^{\text {th }}$ ed. Cunningham FG (ed.). McGraw-Hill Publishers, New York 2005: 443-471.

28. Gebuza G, Szewczyk M, Kaźmierczak M, et al. Ocena czynności serca płodu w IIItrymestrze ciąży podczas słuchania utworów Maurice' a Ravela i Johanna Straussa [Evaluation of fetal heart rate in the third trimester of pregnancy while listening to music Maurice Ravel and Johann Strauss]. Nowa Pediatria 2015; 4: 144-149.

29. Galazios G, Tripsianis G, Tsikouras P, et al. Fetal distress evaluation using and analyzing the variables of antepartum comput- erized cardiotocography. Arch Gynecol Obstet 2010; 281 (2): 229-233.

30. Dawes GS, Lobb M, Moulden M, et al. Antenatal cardiotocogram quality and interpretation using computers. Br J Obstet Gynaecol 1992; 99 (10): 791-797.

31. Fink NS, Urech C, Isabel F, et al. Fetal response to abbreviated relaxation techniques. A randomized controlled study. Early Hum Dev 2011; 87 (2): 121-127.

32. Dawes GS, Moulden M, Redman CW. Computerized analysis of antepartum fetal heart rate. Am J Obstet Gynecol 1995; 173 (4): 1353-1354.

33. Amorim-Costa C, Costa-Santos C, Ayres-de-Campos D, Bernardes J. Longitudinal evaluation of computerized cardiotocographic parameters throughout pregnancy in normal fetuses: a prospective cohort study. Acta Obstet Gynecol Scand 2016; 95 (10): 1143-1152.

34. DiPietro JA, Costigan KA, Nelson P, et al. Fetal responses to induced maternal relaxation during pregnancy. Biol Psychol 2008; 77 (1): 11-19.

\section{AUTHORS' CONTRIBUTIONS}

GG prepared the concept of the manuscript. NS collected data. GG and NS conducted data analysis. GG wrote the manuscript. All authors took part in preparing the final version of the analysis. 